Allan James*

University of Klagenfurt
UDK 801.61:316.472.4

DOI: 10.4312/linguistica.57.1.137-149

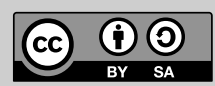

\title{
PROSODY AND PARALANGUAGE IN SPEECH AND THE SOCIAL MEDIA: THE VOCAL AND GRAPHIC REALISATION OF AFFECTIVE MEANING
}

\section{INTRODUCTION}

The ubiquitous use of 'the new digital media' for casual communication and the accompanying - much commented on - new forms and styles of written language employed in 'texting,' 'posting' and 'blogging' compel a re-assessment of hitherto developed linguistic conceptualisations and understandings of informal interchange and their associated models of description. Accepting the fact that both formal and functional analyses of casual communication are overwhelmingly predicated on spoken interlocution, it is a matter of some urgency that the 'new' written mode of interaction exemplified in the social media of, e.g. text messaging, chat, Facebook and Twitter is addressed in linguistic analysis. The linguistic study of CMC (Computer-Mediated Communication) has often focussed on details of the neologisms and non-standard orthography characteristic of such casual written 'conversation' (Crystal 2006, 2008) to the exclusion of attention to the discoursal nature of such communication. One point of entry into the analysis of this 'typed conversation' (Vandekerckhove/Nobels 2010) has been to examine the extent to which this written, but nonetheless 'speech-like,' discourse (Tagg 2012) can be said to reflect the prosodic and paralinguistic features of oral communication. In particular, since the communicative orientation of such mediated discourse is by definition social one might even expect that it would evidence prosody-like and paralanguage-like constructions functioning to signal the affective and social meanings that these suprasegmental and paralinguistic systems can convey in speech. It will be the purpose of the discussion below to investigate this standpoint in some detail, ultimately also drawing attention to the ways in which these interpersonal meanings are expressed by this written mode in its own right.

\section{PROSODIC AND PARALINGUISTIC FEATURES (IN SPEECH)}

Modern linguistic interest in (prosodic and) paralinguistic features of language was first motivated in structuralist theory by the question of which types of vocal utterance belonged to language, i.e. were truly 'linguistic,' as opposed to those which were to be considered 'prelinguistic,' 'nonlinguistic,' 'metalinguistic' or as 'paralanguage' (Trager 1958). The criteria for this taxonomy were mainly formal, but also to some extent functional in nature. For instance, 'voice set,' classified by Trager as 'prelinguistic,' is described as "the idiosyncratic, including the specific physiology of the speakers

* allan.james@aau.at 
and the total physical setting" (1958: 5). 'Voice qualities,' which constitute the main categories of 'paralanguage,' are "modifications of all the language and other noises" (sic), functioning in systematic association with language (1958: 5): they comprise pitch range, vocal lip control, glottis control, pitch control, articulation control, rhythm control, resonance and tempo. Trager posits a connection of 'voice qualities' to prelinguistic 'voice set' as together representing the "overall or background characteristics of the voice" (1958: 5). Thus whereas the physiology of a speaker's vocal tract forms the ultimate organic backdrop to the sound of his or her voice ('voice set'), the effects of this are filtered by the characteristic control the speaker exercises over the functional elements of voice production (pitch range, vocal lip control, glottis control, etc.) which physically derive from the vocal apparatus. Hence, this form of paralanguage is conceived as those patterns of vocal utterance which mediate between the physical prelinguistic and the meaningfully structured linguistic in speech production.

However, other categories of paralanguage are posited which are remote from any linguistic relevance, namely the 'vocalisations' (i.e. "variegated other noises, not having the structure of language" (1958: 5)) distinguished as 'vocal characterisers' (e.g. laughing, crying, sobbing, groaning, belching, etc.), 'vocal qualifiers' of intensity, pitch height and extent, and 'vocal segregates' such as hesitation noises, snorts and sniffs. In practice very little empirical analysis was conducted by Trager and his associates on paralanguage. Prosody was in structuralist linguistics in any case largely subsumed under suprasegmental phonology and only of theoretical relevance if amenable to phonemicisation.

In subsequent research, Crystal refines the analysis of the prosodic and paralinguistic features of English significantly (Crystal/Quirk 1964; Crystal 1969, 1975). Analysing recordings of spontaneous speech from the developing Survey of English corpus via both auditory judgements and spectrographic display, Crystal distinguishes the prosodic features or systems of 'tone (pitch direction),' 'pitch-range,' 'pause,' 'loudness,' 'tempo,' 'rhythmicality' and 'tension,' which is equally considered as a paralinguistic feature or system together with 'voice qualifiers' (including the phonation types 'whisper,' 'breathy' and 'husky' voice, 'creak' and 'falsetto') and 'voice qualifications' (laugh, giggle, 'tremulous,' 'sob' and 'cry') (Crystal 1969: 126-194). These 'voice qualifiers' and 'voice qualifications' are shown to be definable as the total of their values in the system of twelve articulatory and phonatory parameters responsible for continuous variation in vocal production such as air pressure, pulsation type, vocal cord amplitude, tension of supraglottals, etc. (1969: 132ff.) - see further discussion below. In this way paralinguistic features are shown to be the product of the same set of vocal parameters responsible for prosodic variation (and, one might add, segmental variation - see also further discussion below). Finally, Crystal also posits the 'non-linguistic features' of 'voice quality' (similar to Trager's 'voice set') and 'vocal reflexes' (comparable to Trager's 'vocal segregates').

Comparing these two most influential schemes of (prosodic and) paralinguistic features, one notes that Trager's 'voice qualities' correspond broadly to Crystal's 'voice qualifiers,' his 'vocal characterisers' to the latter's 'voice qualifications,' whereas the former's 'vocal qualifiers' are subsumed under Crystal's prosodic features (for an extensive critical comparison of Trager's and Crystal's schemes in the light of voice 
characteristics in general, see James 1978). It will be apparent that Crystal's taxonomy offers an integrated treatment of paralinguistic and prosodic features, unburdened by structuralist requirements that to qualify as linguistically significant the latter must be analysable as segment-type distinctive contrasts. All the prosodic features are gradable: e.g. 'tone' as 'simple,' 'complex,' 'compound' nuclear tones; 'rhythmicality' as 'rhythmic'-'arhythmic,' 'spiky'-'glissando,' 'staccato'-'legato' much as the paralinguistic features are also multi-valued. Crystal expounds on all three features/systems at great length, drawing on empirical analysis and providing a number of illustrative prosodic and paralinguistic transcriptions of data from the Survey of English corpus. In addition to this analysis, Crystal also abstracts from the description of prosodic features a full theory of English intonation (1969: 195-308).

However, as might be deduced from this discussion, the field of inquiry into paralinguistic features might be seen to suffer from a certain arbitrariness of classification and general lack of theoretical underpinning (in comparison, the field of prosodic features is far further developed in theory and analysis and will not be expanded on greatly in the present context). Crystal himself takes the study of paralanguage to task for such shortcomings, listing seven different formulations in the literature of what vocal phenomena paralanguage is said to include (1975: 51-64), at the same time confirming that "there is a need for a more broadly-based view of the functional role of paralanguage and its relation to non-linguistic effects" (1975: 62). He adds at the same time - relevantly for the discussion below - that with regard to the existing literature of the time "[F]unctional definitions purely in terms of 'emotional' or 'affective' information are inadequate... and a social function for paralanguage is only occasionally (and vaguely) referred to" (1975: 62). However, concerning the general social embedding of paralanguage in communication, Crystal does note that it (and prosody, as non-segmental features) need to be seen together with other linguistic and non-linguistic 'vocal effects' within a 'semiotic frame' of communication for interpretation (1975: 92-95). To the extent that this frame of reference is understood to be indexical, then speaker characteristics with regard to sex, age, status, occupation and speech style (genre) can thus be signalled (1975: 85-92).

In conclusion it might be noted that despite this signalled 'semiotic turn' in structurally oriented linguistics starting in the 1960s and 1970s, there has been little progress in connecting the linguistics - and 'non-linguistics' - of voice characteristics with social meaning in this respect (but $c f$. ., e.g., Henton/Bladon (1988) and the earlier programmatic remarks of Laver concerning the paralinguistic significance of 'settings,' i.e. voice quality, "in signalling affective information through tone of voice, and regulating the progress of conversational interactions" (1980: 3)). It is mainly the subsequent everexpanding research into the linguistics of verbal exchange within sociolinguistics and related fields ( $c f$. in particular Jefferson (1984) in the field of Conversation Analysis) that has facilitated a renewed interest in paralanguage (and a continuing one in prosody) as an expression of the social semiotics of participant interlocution. A more recent suitable and succinct definition of paralanguage is offered by Wennerström (2001) as "the variation of pitch, volume, and voice quality that a speaker makes for pragmatic, emotional, and stylistic reasons and to meet the requirements of genre" (2001: 60). 
Considering prosody, in practice, most linguistic analysis in the last fifty years been conducted within the context of intonation research. The study of linguistic prosody has during this time gradually shifted its orientation from the analysis of intonation as a phonetic/phonological system via the analysis of intonation as spoken text to the analysis of intonation in its conversational function. These developments in intonation research may be represented in the following schema as successive, but partially overlapping, phases:

$\begin{array}{lll}\text { INTONATION IN/AS } & > & \text { INTONATON IN/AS } \\ \text { SYSTEM } & \text { TEXT } & \begin{array}{l}\text { INTONATION IN/AS } \\ \text { CONVERSATION }\end{array} \\ \text { unit structuring } & \text { unit sequencing } & \text { unit turns } \\ \text { focus on substance } & \text { focus on discourse } & \text { focus on interlocutor } \\ \text { propositional meaning } & \text { textual meaning } & \text { interpersonal meaning } \\ \text { (e.g. Crystal 1969) } & \text { (e.g. Brazil 1975) } & \text { (e.g. Szczepek Reed } \\ & & \text { 2006) }\end{array}$

The earlier work on intonation (e.g. Crystal 1969) as INTONATION IN SYSTEM strove to extend the phonetic details of 'linguistically structured prosody' beyond pitch and stress and it at the same time developed a refined conception of intonational unit patterning as tone type, nucleus and tone-unit (e.g. via the systems of tone, tonicity and tonality of Halliday (1967)); the predominant (but not sole) intonational meaning focussed on was the propositional (Halliday's 'ideational'). In the subsequent phase of INTONATION IN TEXT (e.g. Brazil 1975, 1977) attention turned to how structural choices of tone, 'key' and 'termination' in successive tone units shape the continuity and cohesion of spoken discourse, hence highlighting the textual meaning of intonation. In the more recent phase of INTONATION IN CONVERSATION (e.g. Szczepek Reed 2006; $c f$. also Couper-Kuhlen/Selting 1996), studies have investigated the way in which the intonational choices of interlocutors shape the flow of oral exchange, for instance by signalling turn-takes, where the meaning intonation carries is interactionalinterpersonal in nature. However, at the same it will be noted that even in this 'interpersonal' function, intonation structure is not seen as systematically expressing affective or social meanings as such.

Returning again to paralanguage, its linguistic study over this equivalent time has been conspicuously meagre. However, and perhaps ironically, it is with the upsurge of written, but 'speech-like' (?) casual 'conversation' via the new social media that questions as to the interpersonal and social significance of 'paralinguistic' (and 'prosodic') features in such communication have begun to emerge.

\section{PROSODIC AND PARALINGUISTIC FEATURES IN WRITING?}

\subsection{Read-aloud Prosody}

The connection between prosody and paralanguage and written language has been explored in the pre-social media age as a rendering of the one in the mode of the other; specifically via the analysis of read-aloud prosody and written paralanguage. Chafe 
(1988), for example, is convinced of the 'covert prosody' of written language which "is apparent to a reflective writer or reader" and via which writers and readers "experience auditory imagery of specific intonations, accents, pauses, rhythms, and voice qualities, even though the writing itself may show these features poorly if at all" (1988: 397). "The principal device for making prosody at least partially overt" (1988: 397) is punctuation; with full stops, question marks, exclamation marks, commas, colons, semi-colons, dashes and brackets having the potential of marking (certain) intonation unit boundaries in written language read aloud as well as signalling rhythmic pauses. However, in reality punctuation functions primarily in the service of grammatical structure by marking syntactic unit boundaries of different dimensions. To establish how punctuation marks correlate with intonation unit boundaries and with the pitch patterns of falling and rising, Chafe analyses the reading aloud of various texts (advertisement, newspaper, academic text and three literary passages) by younger (20 year old) and older (64 year old) informants, in which it is shown that while intonation unit boundaries in general coincided with the punctuation marks, certain intonation unit boundaries were not signalled by punctuation, and that the majority of the punctuation marks (i.e. '., ', ', ',', ':' and '?' ) coincide with a falling pitch except commas, most of which coincided with a 'nonfalling' pitch (1988: 408-409).

As interesting as this research might be, it may be pointed out that the written passages are read in a particular style as 'spoken prose' (Abercrombie 1956), i.e. as written language vocalised in a particular style of delivery (with conventional tempo, pausing, pitch range and volume as well as pitch patterns and segment articulation), and remembering too perhaps that the standard orthography of a written text is not a transcription of speech. In other words, in investigating the position of prosody with regard to written language, the vocal essence of the former in the spoken mode of language must be explicitly related (e.g. transformed or converted) into a graphic essence in the written mode of language for comparisons and correlations to be made. Of course the meanings or functions expressed by prosody in language may be compared from speech to writing and the extent to which its meaning is constrained and determined by the affordances of the spoken mode in which it is embedded is a question still to be addressed.

\subsection{Written Paralangage: Its Representation in Literary Prose}

Examining the relationship between the written language and paralanguage, Brown (1977) proceeds in an opposite direction by investigating how paralinguistic features are 'directly' represented in writing. Defining the paralinguistic features of speech as "those which contribute to the expression of attitude by the speaker. They are phonetic features of speech which do not form an intrinsic part of the phonological contrasts which make up the verbal message" (1977: 2), but noting the variety of interpretations as to which specifically vocal features they are, Brown proceeds to establish her own list for English Language Teaching purposes. They exclude any specifically intonation and rhythm features and comprise: 'pitch range,' 'placing in voice range,' 'tempo,' loudness,' 'voice setting,' 'articulatory setting,' 'articulatory precision,' 'lip setting,' 'direction of pitch,' 'timing' and 'pause.' It will be apparent that this framework includes 
both the 'prosodic' and 'voice quality' features of other models. Further, each feature manifests 'unmarked' and 'marked' values: e.g. 'pitch span' can be 'unmarked,' 'extended' or 'restricted' and 'voice setting' can be 'unmarked,' 'breathy' or 'creaky.'

By way of operationalising the features for teaching purposes, Brown then illustrates the attitudinal and emotional effect carried by them by presenting how these features probably underlie the formulation of reporting clauses (of direct speech) in literary sources. Thus, for example, while the reporting verbs replied, answered and said reflect unmarked values of all features, the inclusion of the adjectives depressed and miserable and the adverb sadly in reporting clauses could reflect 'restricted pitch span,' 'lowered placing in voice range' and 'slow tempo,' but at the same time unmarked values of the remaining features (1977: 149). The assumption here of course is of a direct link between the written mode and the spoken mode of language, in that the former can be said to represent the latter transmodally from vocal substance to graphic substance indirectly in the present case via lexical description (as opposed to more directly in the form of transcription). While the postulation of this connection must, strictly speaking, be explictly argued for (see above and further discussion below), this didactically motivated operationalisation of paralinguistic features is nonetheless unique.

\section{4 'PROSODY' AND 'PARALANGUAGE' IN THE NEW SOCIAL MEDIA}

\subsection{The Linguistics of Speech and Writing}

It has been commented in the Introduction above that since the 'new' digital media are now employed on a large scale for interpersonal communication, with the conveying of social and affective meanings predominant, it would not be surprising if the language used in such interchanges reflected in a graphic modality the ways in which these meanings are expressed in a comparable vocal one by means of prosody and paralanguage. The fact that one type of such written discourse is actually referred to as chat belies an orientation in genre classification to 'original' oral models, and it is in digitally mediated social writing that linguistic style has become overtly reflective of 'equivalent' speech. However, as indicated already in the previous discussion above, this relation of comparability between speech and writing, vocality and graphicality and therefore 'spoken' and 'written' prosodic and paralinguistic features must be explicitly analysed and not simply assumed to be given, for an understanding of the forms and functions of 'equivalent' linguistic expression within the affordances of the respective modality. Drawing selectively on data from two relevant corpora for representative illustration - the CorTxt text messaging corpus of Tagg (2012) and the HERMES microposts corpus presented by Zappavigna (2012) - these issues will be pursued in detail in the following.

The observation that linguistics at least since Saussure has focussed its analysis on spoken as opposed to written language is a truism. This 'phonocentrism' (Deumert 2014), where the spoken language has also been 'the object of the sociolinguistic gaze' (Lillis 2013), has in recent years been increasingly exposed by the challenges for analysis raised by digital writing. In particular, analysis not only of the styles of language use now associated with the new media, but also of the digital medium itself and its 
graphic modality has become an urgent requirement for progress in linguistic understanding. Analysis of both structural and semiotic (semantic and pragmatic) properties and typicalities of $\mathrm{CMC}$ leads inevitably to reflection on the affordances and constraints for expression the medium creates and hence also to a greater understanding of how 'typed' digital screen writing departs linguistically from 'typed' print on paper writing.

In an overview of how theorising writing has developed over time, Lillis (2013: 150-161) traces how the 'key academic frames' with their associated fields of activity have emerged successively. The specifications of certain of them may be represented thus ( $c f$. Lillis 2014: 160-161; Table 7.1, here in abridged and adapted form):

\begin{tabular}{|c|c|c|c|c|}
\hline FRAME & $\begin{array}{l}\text { poetic- } \\
\text { aesthetic }\end{array}$ & $\begin{array}{l}\text { transactional- } \\
\text { rationalist ... }\end{array}$ & social semiotic & socio-discursive \\
\hline \multirow[t]{2}{*}{ FIELDS } & $\begin{array}{l}\text { literary } \\
\text { studies }\end{array}$ & linguistics & semiotics & applied linguistics \\
\hline & & & $\begin{array}{l}\text { linguistics } \\
\text { multimodality }\end{array}$ & $\begin{array}{l}\text { sociolinguistics } \\
\text { critical discourse }\end{array}$ \\
\hline
\end{tabular}

Here it will be apparent that linguistics has 're-invented' itself from its original 'transactional-rationalist' approach to writing to a more recent social semiotic frame of research and as sociolinguistics to a socio-discursive approach. Indeed the linguistic analysis of socially oriented digital writing needs to be conducted within appropriate semiotic and discursive frames of reference (not just the 'transactional-rationalist') to fully elucidate the contextual significance of such texts and practices.

\section{2 'Prosody' and 'Paralanguage': Formal Properties in Speech and Writing}

As to the nature of prosody and paralanguage and their relation to digitally mediatised social discourse, a reconsideration of their 'original' formal and functional properties in speech is necessary. Concerning formal essence, it may be deduced from the discussion in 2 above of Crystal's parametric framework for his paralinguistic features of 'voice qualifiers' and 'voice qualifications' (1969: 132-135) that in physical terms also prosodic (and segmental!) vocal effects are brought about by variation along the same phonatory and articulatory parameters of the vocal apparatus. They are in full (1969: 135):

air pressure - oral aspiration - nasal friction - pulsation type - pulsation speed - phase with syllable - vocal cord amplitude - vocal cord vibration - volume of supraglottals - tension of supraglottals - extent of horizontal glottal movement - ingressive airflow*

With the exception of 'ingressive airflow' (marked '*'), these parameters can be seen to vocally define for instance prosodic - and segmental - realisation in Standard British English pronunciation; e.g. prosodically as the phonetic systems of pitch (height-direction (range-span)), volume and duration (and thereby phonological 
intonation and stress) - and segmentally as the phonetic systems of voicing, length, nasality and aspiration. The particular values of the combination of parameters in association with particular co-occurring lexis determine their interpretation as locally 'prosodic' or 'paralinguistic.'

Reflecting now on the mechanisms of (digital) writing production and their propensity for realising prosody-equivalent and paralanguage-equivalent forms, there are typographic limitations to the typical keyboard with its letter and numeral characters, punctuation marks, mathematical '+', '-', '=' and '\%', ' $\&$ ', '@' and a limited number of currency signs. While the letter 'alphabet' might be seen as 'equivalent' to the segment system of speech, following Chafe (1988) the punctuation marks '.', ',', '!', '?', ' $:$ ', and ';' might be seen to be 'equivalent' to the intonation system of pitch direction (tone) and unit termination (tonality). By extension, the punctuation marks '( )', '[ ]', ' \{\} ', and also " "' could be said to equate contextually to onset and termination of intonation unit (tonality), respectively. However note that these 'equivalences' are with elements and features of a phonological status in speech. Indeed the typographic limitations of a keyboard as alphabet permit the conventional orthographic realisation of the particular language in type/print much as the segment inventory of the language would constitute the basis for phonological realisation in speech. Of course the forms of the letters themselves on the keyboard follow particular script conventions of alphabetic writing, e.g. Roman, Cyrillic, Greek, etc. Punctuation marks signal linear divisions in the (typo-)graphic display on screen or page according to grammatical criteria, marking phrase, clause and sentence boundaries variously, sentence type (declarative/interrogative/imperative) and direct 'speech' (?) mode boundaries.

It will be apparent from these reflections that the formal essence of written language typography cannot in any direct way be compared to the formal essence of spoken language prosody and paralanguage. In any case the nature of the written mode compels a representation of language in space, while the spoken mode is produced as vocal events in time. While typographic writing selects pre-formed characters from a keyboard layout to produce lexical units according to the orthographic conventions of the language sequentially, the prosodic and paralinguistic features of speech are formed via physical configurations of the vocal tract producing vocal effects which co-realise the phonetic essence of lexical units simultaneously.

\subsection{Representing 'Prosody' and 'Paralanguage' in Digital Writing: The Re- semioticisation of Punctuation and Orthography}

Any attempt to represent (not reproduce!) the linguistic effects of prosody and paralanguage in 'typed conversation' must re-interpret the semiotics of the keyboard characters and signs. In other words, it is obviously the functions of prosodic and paralinguistic features that are re-created not the forms in any way, and these functions are realised as value-added affective and social meaning of the lexical substance produced. Hence one such a typical 're-semioticisation' of the keyboard symbols takes the form of reindexing indexical punctuation marks, e.g. by which the semiotics of '!' shifts from its grammatical function as boundary marker of exclamatory-declarative sentences to a 
general marker of emotional intensity, or iconicising ';', which changes from punctuation index of grammatical break to icon meaning something like humorous scepticism. Other familiar examples of punctuation marks re-semioticised are:

'?' as indexical marker of curiosity, doubt, etc.

' $?$ ' as iconic eyes

')' as iconic mouth, upturned as in smiling

'(' as iconic mouth, downturned as in grimacing

These punctuation marks and others and also letter characters combine together to form lexis-like pictograms known as 'emoticons' which express general attitudes and emotions such as in the following (taken from the CorTxt corpus):

i. ':)' happiness as in "5.36 Glad it went well :)" and

ii. ':-' happiness as in "5.39 ...hope you got train ok :-)"

(Tagg 2012: 119)

iii. ':(' sadness as in "5.37 ...sorry I didn't make it over to you :(" and

iv. ':-(' sadness as in "5.45 Apparently there's a huge queue :-("

(Tagg 2012: 120)

Numerous other examples and combinations could be given from the 190,000 word CorTxt corpus (Tagg 2012) and the 7 million tweet HERMES corpus (Zappavigna 2012), where the whole system of emoticons and their composition is presented in considerable detail (2012: 73-76). The exact formulation of the attitudes they express can be refined per context, e.g. as 'regret' in iii. above and 'frustration' in iv. It will be noticed that the emoticons are realised after the verbal structure, in principle qualifying the whole utterance they follow. These punctuation-derived emoticons are now being increasingly substituted by easily accessible non-keyboard 'smileys' (where, e.g., ':-(' becomes $(\theta)$ ) as well as whole sets of emojis and other pictographic images, etc.

Another re-semioticisation of keyboard symbols takes the form character repetition indicating intensification of emotion or attitude as in the examples from the HERMES corpus:

v. 'iiiiiiii' as in "\# nowplaying We gotta liiiiiiiive like we're dying"

(Zappavigna 2012: 57)

or punctuation mark repetition:

vi '!!!' as in 'User oh My. God. You are the most awesome person ever :D THANK YOU !!!

(Zappavigna 2012: 68)

This last example also shows the use of 'caps lock' as an intensification of the emotion expressed by the lexis as well as the emoticon ':D', a re-semioticised punctuation mark plus upper case letter signalling joy, plus re-semioticised full stops in "oh My. God." standing for radical pause in the discourse. 
In prosodic terms the repetition of letter characters would seem to correspond to the duration feature and the capitalisation to the feature loudness. As 'prosody-like' they are linked to lexical units directly. However, these are nonetheless indexical and not iconic graphic symbols and therefore symbolically remote from prosody, while noting the shared prosodic-graphic operationalisation of this intensification as greater length by prolonging and greater intensity by magnifying.

A link to paralanguage would seem to be given with the emoticons above, which serve the expression of affective (attitudinal and emotional) meaning directly via iconic face-like symbols separate from the lexical structure and thereby presumably qualifying longer stretches of utterance. They have nonetheless quasi-lexical character themselves as logograms (punctuation based) and pictograms (smileys). The affective meanings depicted would in speech most likely be expressed via the 'voice qualifications' of paralanguage combined with actual facial expression. However, it must be remembered that the emoticons and emojis are typographic-pictographic not paralinguistic symbols: the character repetitions and capitalisations are orthographic-logographic not prosodic symbols. The means of their semiotic signalling as 'reinforcing the signal,' and their linguistic co-occurrence are at a certain level of abstraction reminiscent of prosodic and paralinguistic features.

Many other examples could be given of the logograms and respellings of the social media and their analysis (cf. Deumert 2014: 122-145; Tagg 2012; and Zappavigna 2012 for extensive treatment), but perhaps at this point the socio-discursive essence of social media interchange could be addressed by establishing why the analogy of prosodic and paralinguistic communication has been considered to be so illuminating.

\subsection{The Expression of Affective Meaning}

As already indicated, communication via the digital media serves the cultivation of interpersonal contact in a medium conducive to informative-commentative collaboration, to a 'mediated phatic sociability' (Miller 2008), and to the construction of an 'ambient affiliaton' (Zappavigna 2012) and within such an ambience the expression of affective meaning is greatly furthered. At the same time social identities are being created and performed via the linguistic choices being made (Tagg 2012: 169-190) and an informal style of verbal-visual interlocution maintained. The written/typed mode of its realisation itself allows a degree of reflexivity on the part of the interlocutors (e.g. the affordance of 'deliberate' language use). These factors collude to encourage texters to express affective stance and evaluation with regard to their subject matter relatively freely. In terms of appraisal theory (Martin/White 2005) they employ 'upscaled graduation, tending to intensify interpersonal systems as a way of increasing solidarity through emphasizing both positive and negative appraisal as shared experience' (Zappavigna 2012: 67). While in this theory both the present 'more prosodic' capitalisations and character repetitions and the 'more paralinguistic' smileys, emoticons and emojis predominantly signal the 'affect' meaning feature, but by extension also the 'judgement' and 'appreciation' features of the 'attitude' system (cf. Zappavigna 2012: 53ff.), the former are message-oriented and vocally-linked in substance and the latter 
interlocutor-oriented and gesturally-linked in substance. In summary, Tagg characterises the mindset of the texter succinctly thus:

the main concern is not to 'sound speechlike' but to fulfil interpersonal purposes to express an evaluative stance, to heighten intimacy, to signal informality. The norms that are typically associated with spoken language can be seen as resources that texters draw on in creating an impression and intimacy. Thus, if you like, they are performing a speech-like informality, just as they perform being brief and non-standard.

(Tagg 2012: 183)

\section{CONCLUSION}

The 'prosodic' and 'paralinguistic' continue to pervade the literature on blogging and texting as points of reference, as the following quotes demonstrate: Zappavigna states that "Interpersonal meaning is difficult to study because it is prosodic in nature" (2012: 10) and that "emoticons manifest prosodically" (2012: 73); 'paralinguistic restitution' is used by Tagg (2012: 48) to refer to the character repetitions and capitalisation discussed above; Tagg further posits that "the lack of paralinguistic cues" encourages texters to use emoticons (2012: 122) and that performing identity online means "reduced access to paralinguistic features" (2012: 176); and finally, and tellingly, Zappavigna concludes that language used in the social media "is deployed in a modality whose interpersonal meanings that might otherwise be expressed paralinguistically must be expressed with other means" (2012: 195, fn. 7).

These statements confirm the persistence of the general notion that the prosodic and paralinguistic somehow underlie social media communication as constituting the 'original' (more adequate?) verbal means of expressing the interpersonal semiotics that the latter strives (imperfectly?) to convey. However, it has been shown that texters and bloggers do not perform prosodic and paralinguistic features as such, but rather, in Tagg's terms, a 'speech-like' discourse, one which with its graphic modality creates its own conventions of verbal expression that are selectively reminiscent, formally, of a written transcription of prosodic and paralinguistic effects and, functionally, of the affective meanings that the latter can convey.

In current reality, with the 'keyboards' of mobile texting devices no longer containing punctuation marks or any characters other than those required for spelling and with the online availability of ever increasing numbers of emoticons and emojis, the graphic means of producing so-called 'prosodic-like' and 'paralinguistic-like' meanings in social media discourse has in fact never been greater.

\section{References}

ABERCROMBIE, David (1956) Problems and principles in language study. London: Longman.

BRAZIL, David (1975) Discourse intonation. Birmingham: English Language Research, University of Birmingham. 
BRAZIL, David (1977) Discourse intonation II. Birmingham: English Language Research, University of Birmingham.

BROWN, Gillian (1977) Listening to spoken English. London: Longman.

CHAFE, Wallace (1988) "Punctuation and the prosody of written language." Written Communication 5/4, 395-426.

COUPER-KUHLEN Elizabeth/Margret SELTING (eds) (1996) Prosody in conversation. Cambridge: Cambridge University Press.

CRYSTAL, David (1969) Prosodic systems and intonation in English. Cambridge: Cambridge University Press.

CRYSTAL, David (1975) The English tone of voice. London: Edward Arnold.

CRYSTAL, David (2006) Language and the internet. Cambridge: Cambridge University Press.

CRYSTAL, David (2008) Txting: The gr8 db8. Oxford: Oxford University Press.

CRYSTAL, David/Randolph QUIRK (1964). Systems of prosodic and paralinguistic features in English. The Hague: Mouton.

DEUMERT, Ana (2014) Sociolinguistics and mobile communication. Edinburgh: Edinburgh University Press.

HALLIDAY, Michael (1967) Intonation and grammar in British English. The Hague: Mouton.

HENTON, Clive/Anthony BLADON (1988) "Breathiness in a normal female speaker: inefficiency versus desirability." Language and Communication 5, 221-227.

JAMES, Allan (1978) "Voice characteristics in theory and practice." In: H.P. Kelz (ed.), Phonetische Grundlagen der Ausspracheschulung. Hamburg: Buske, 1-28.

JEFFERSON, Gail (1984) “Transcript notation.” In: J. Atkinson and J. Heritage (eds), Structures of social action: Studies in conversation analysis. Cambridge: Cambridge University Press, ix-xvi.

LAVER, John (1980) The phonetic description of voice quality. Cambridge: Cambridge University Press.

LILLIS, Theresa (2013) The sociolinguistics of writing. Edinburgh: Edinburgh University Press.

MARTIN, James/Peter WHITE (2005) The language of evaluation: appraisal in English. New York: Palgrave Macmillan.

MILLER, Vincent (2008) "New media, networking and phatic culture". Convergence: The International Journal of Research into New Media Technologies 14/4, 387400. http://dx.doi.org/10.1177/1354856508094659

SZCZEPEK REED, Beatrice (2006) Prosodic orientation in English conversation. London: Palgrave Macmillan.

TAGG, Caroline (2012) The discourse of text messaging. London: Continuum.

TRAGER, George (1958) "Paralanguage: a first approximation." Studies in Linguistics $13,1-12$.

VANDEKERCKHOVE, Reinhild/Judith NOBELS (2010) "Code eclecticism: linguistic variation and code alternation in the chat language of Flemish teenagers." Journal of Sociolinguistics 14, 657-677. http://dx.doi.org/10.1111/j.1467-9841.2010.00458.x 
WENNERSTRÖM, Ann (2001) The music of everyday speech. Oxford: Oxford University Press.

ZAPPAVIGNA, Michele (2012) Discourse of Twitter and social media. London: Bloomsbury.

\section{Abstract \\ PROSODY AND PARALANGUAGE IN SPEECH AND THE SOCIAL MEDIA: THE VOCAL AND GRAPHIC REALISATION OF AFFECTIVE MEANING}

The study of prosody and paralanguage is in the first place concerned - unsurprisingly - with the phonetic and linguistic effects of non-segmental vocal variation expressed as values of the feature systems of pitch, volume and duration, but also of rhythm and tempo and further of voice qualities, etc. However, in more recent times the emergence of digitally mediated written communication (in the 'new' social media) has led attention to the role of prosody and paralanguage in defining the characteristic informal interpersonal style of this new 'typed conversation.' The present article reviews the formal and functional essence of prosody and paralanguage and, drawing on data from recent corpora of text messaging and microblogging, analyses the extents to which prosodic and paralinguistic features may be reflected in such discourse, in particular the ways in which affective meaning is expressed in the graphic modality of this medium.

Keywords: paralanguage, prosody, speech, writing, social media

\section{Povzetek \\ PROZODIJA IN PARAJEZIK V GOVORU IN DRUŽBENIH OMREŽJIH: GLASOVNA IN GRAFIČNA URESNIČITEV AFEKTIVNEGA POMENA}

Raziskave prozodije in parajezika se ukvarjajo predvsem s fonetičnimi in jezikovnimi učinki nesegmentnih glasovnih sprememb, ki se odražajo $v$ glasovni višini, glasnosti in trajanju, kakor tudi $\mathrm{v}$ ritmu, tempu in glasovnih značilnostih. V zadnjem času pa je pojav digitalno posredovanega pisnega sporazumevanja (»novi« družbeni mediji) usmerilo pozornost na vlogo prozodije in parajezika pri določanju značilnega neformalnega medosebnega sloga te nove oblike »tipkane konverzacije«. Članek ocenjuje formalno in funkcijsko bistvo prozodije in parajezika. Na osnovi analize podatkov iz novejših korpusov kratkih besedilnih sporočil in mikroblogov ugotavljamo, v kolikšni meri se prozodične in parajezikovne lastnosti lahko odražajo v takšnih besedilih. Še posebej nas zanimajo načini, s katerimi se afektivni pomen izraža $\mathrm{v}$ grafični podobi tega medija.

Ključne besede: parajezik, prozodija, govor, pisanje, družbeni mediji 